\title{
Stability of Platinum in Sulfuric Acid Solution Studied by Electrochemical Quartz Crystal Microbalance
}

\author{
Amar Prasad Yadav ${ }^{*}$ \\ Central Department of Chemistry, Tribhuvan University, Kirtipur, Kathmandu, Nepal \\ Email:amar2y@yahoo.com
}

\begin{abstract}
The stability of electrodeposited platinum electrode in $0.5 \mathrm{M} \mathrm{H}_{2} \mathrm{SO}_{4}$ solution has been studied under potentiodynamic and potentiostatic conditions using electrochemical quartz crystal microbalance $(E Q C M)$. In potentiodynamic polarization, cyclic voltammetry $(\mathrm{CV})$ was carried out from 0.0 to $1.4 \mathrm{~V}$ at the scan rate of $0.01 \mathrm{~V} \mathrm{~s}^{-1}$ while in potentiostatic polarization, potential was stepped from $0.45 \mathrm{~V}$ to higher anodic potential limits of $0.75 \mathrm{~V}, 1.0 \mathrm{~V}, 1.1 \mathrm{~V}, 1.2 \mathrm{~V}, 1.4 \mathrm{~V}$, and $1.5 \mathrm{~V}$ and corresponding mass change resulting from the formation of $P t O$ was measured by EQCM. The results of $C V$ and EQCM revealed that the Pt surface was covered with PtO in $0.65<E<1.5 \mathrm{~V}$.
\end{abstract}

Keywords: Electrodeposited Pt , EQCM, PEFC, Dissolution

\section{Introduction}

Polymer electrolyte fuel cell (PEFC) is being extensively researched as an alternate energy conversion and efficient power source device due to its environmentally clean working condition. One of the key factors limiting the commercialization of PEFC is the stability of Pt catalyst ${ }^{1-3}$. PEFC operating under either constant potential or cycling ON-OFF condition gradually losses performance due to a loss of the electrochemically active surface area at the cathode ${ }^{4}$. Loss of active surface area has been attributed to dissolution-redeposition of $\mathrm{Pt}$ at high potentials typical of the PEFC cathode with the driving force being the high free energy of small platinum particles ${ }^{1}$. Accordingly, the dissolved Pt can either deposit on existing Pt particles to form larger particles by Ostwald ripening process ${ }^{5,6}$ or diffuse into the polymer electrolyte ${ }^{7}$. The deposition of $\mathrm{Pt}$ in electrolyte membrane can lead to its decomposition or increase of resistance, therefore affecting the durability of PEFC.

It is now well known that potential cycling leads to accelerated Pt dissolution and loss of active area ${ }^{8-}$ ${ }^{14}$. In view of the above fact, for the last couple of years, most of the studies on the platinum dissolution have been based on experimenting with potential cycling ${ }^{8-14}$. Nevertheless, PEFC during operating condition remains at steady-state potential for a significant amount of time. But, with the exception of a few studies, ${ }^{6,15-17}$, there is a lack of knowledge regarding the effect of steady-state potential on the dissolution of platinum in polymer electrolyte solution. It is important to know the amount of Pt dissolved at a particular potential as it affects the dissolution-deposition process of $\mathrm{Pt}$ in polymer electrolyte.

In order to understand the elementary steps of Pt dissolution mechanism and therefore minimizing the loss of Pt in PEFC, it is important to know the potential dependence of platinum dissolution in acidic medium under both potential cycling and steady state conditions. This study reports on the EQCM study of Pt dissolution in sulfuric acid solution under cyclic voltammetric and potentiostatic conditions. The electrochemical quartz crystal microbalance (EQCM) was used to determine the mass change during initial stage of polarization so as to know the extent of surface coverage by the formation of the surface Pt-oxide.

\section{* Corresponding author}




\section{Experimental}

Pt samples used in this study were prepared by electrochemical deposition (ECD) process. An AT-cut Au QCM of $10 \mathrm{MHz}$ resonance frequency with the geometrical area of $0.07 \mathrm{~cm}^{2}$ was used as the substrate and $40 \mathrm{mM} \mathrm{H}_{2} \mathrm{PtCl}_{6}$ solution was used as the electrolyte. The electrodeposition was performed in potentiostatic mode at $0.2 \mathrm{~V}$ vs. SHE on one side of the QCM. The Pt-plated Au QCM was then used as a working electrode. The thickness of Pt layer was about $65 \mathrm{~nm}$ with the average particle size of $40-60 \mathrm{~nm}^{18}$.

The cyclic voltammetry and potentiostatic polarization and corresponding mass change were performed using an EQCM system (Hokuto Denko, HQ-304C). Mass change per unit area, $\Delta m$, was calculated from the changes in resonance frequency, $\Delta f$, using the Sauerbrey equation ${ }^{19}$ :

$$
\Delta m=-\left(A_{\text {piezo }} \sqrt{\rho_{q} \cdot \mu_{q}} / 2 f_{0}^{2}\right) \Delta f
$$

where $f_{0}$ is the resonant frequency of the quartz resonator, $\mu_{q}$ is the shear modulus of the quartz $(2.947 \mathrm{x}$ $\left.10^{11} \mathrm{~g} \mathrm{~cm}^{-1} \mathrm{~s}^{-2}\right)$, and $\rho_{\mathrm{q}}$ is density of the quartz $\left(2.648 \mathrm{~g} \mathrm{~cm}^{-3}\right)$. The terms in the bracket represent the sensitivity factor of the QCM. The sensitivity factor for a $10 \mathrm{MHz}$ QCM estimated from its resonant frequency in the test solution was about $4.50 \mathrm{ng} \mathrm{Hz}^{-1} \mathrm{~cm}^{-2}$. Therefore, at the frequency stability of $1 \mathrm{~Hz}$ this EQCM has the mass resolution of $4.50 \mathrm{ng} \mathrm{Hz}^{-1} \mathrm{~cm}^{-2}$.

Electrochemical measurements were made in a one-compartment Teflon cell with 30 ml capacity using $0.5 \mathrm{M} \mathrm{H}_{2} \mathrm{SO}_{4}$. A KCl-saturated silver/silver chloride electrode (SSE) with a double junction was used as a reference electrode and $\mathrm{Au}$ wire was used as the counter electrode. The potential values are referred to the SHE. All the measurements were made at $25{ }^{0} \mathrm{C}$ with solutions prepared in triply distilled water under deaerated condition using nitrogen gas. Before each measurement, Pt surface was washed with water and ethanol, dried it very carefully and set on the oscillating circuit. The cyclic voltammetric measurements were carried out in the potential range between 0.0 and $1.4 \mathrm{~V}$ at $0.01 \mathrm{~V} \mathrm{~s}^{-1}$. From the $\mathrm{CV}$, the electrochemical surface area (ECA) was determined by integrating the charge in the underpotential deposition region of $\mathrm{H}(\mathrm{UPDH})$. All the results are here reported with respect to ECA.

During potentiostatic polarization, potential of the Pt electrode was first kept at $0.45 \mathrm{~V}$ for 3 min, where EQCM stabilized and then it was stepped to a desired potential for $600 \mathrm{~s}$.

\section{Results and Discussion}

\section{Cyclic Voltammogram $(\mathrm{CV})$}

In order to understand the electrical and corresponding mass change response, $\mathrm{CV}$ of a platinum electrode was measured using a $10 \mathrm{MHz}$ EQCM in a deaerated $0.5 \mathrm{M} \mathrm{H}_{2} \mathrm{SO}_{4}$ solution. Figure 1 shows the $\mathrm{CV}$ of an electrodeposited $\mathrm{Pt}$ recorded at $0.01 \mathrm{~V} \mathrm{~s}^{-1}$. The $\mathrm{CV}$ and mass change in between $0 \sim 1.4 \mathrm{~V}$ are divided into three regions, Region I $(0 \sim 0.4 \mathrm{~V})$ : redox of $\mathrm{H}^{+} / \mathrm{H}_{\mathrm{ad}}$ (UPD), Region II $(0.4 \sim 0.65 \mathrm{~V})$ : charging/discharging of electrical double layer (DL), and Region III $(0.65 \sim 1.4 \mathrm{~V})$ : formation/reduction of Pt-oxide.

In the UPD and DL regions, the mass increased almost linearly with shifting the potential in noble direction, though the mass change in the UPD region was slightly influenced by $\mathrm{H}_{\mathrm{ad}}$. In these regions, the mass would change with the applied potential due to adsorption of water molecule $\left(\mathrm{Pt}-\mathrm{H}_{2} \mathrm{O}_{\mathrm{ad}}\right)$ on the platinum electrode ${ }^{20}$.

$$
\mathrm{Pt}+\mathrm{H}_{2} \mathrm{O} \rightarrow \mathrm{Pt}-\mathrm{H}_{2} \mathrm{O}_{\mathrm{ad}}
$$

There was no hysteresis in the mass change response in the DL region. This indicates that the adsorption/desorption reaction of water is very fast and the amount of dissolved platinum is negligibly small in each cycle, compared to the amount of the formed platinum oxides. 

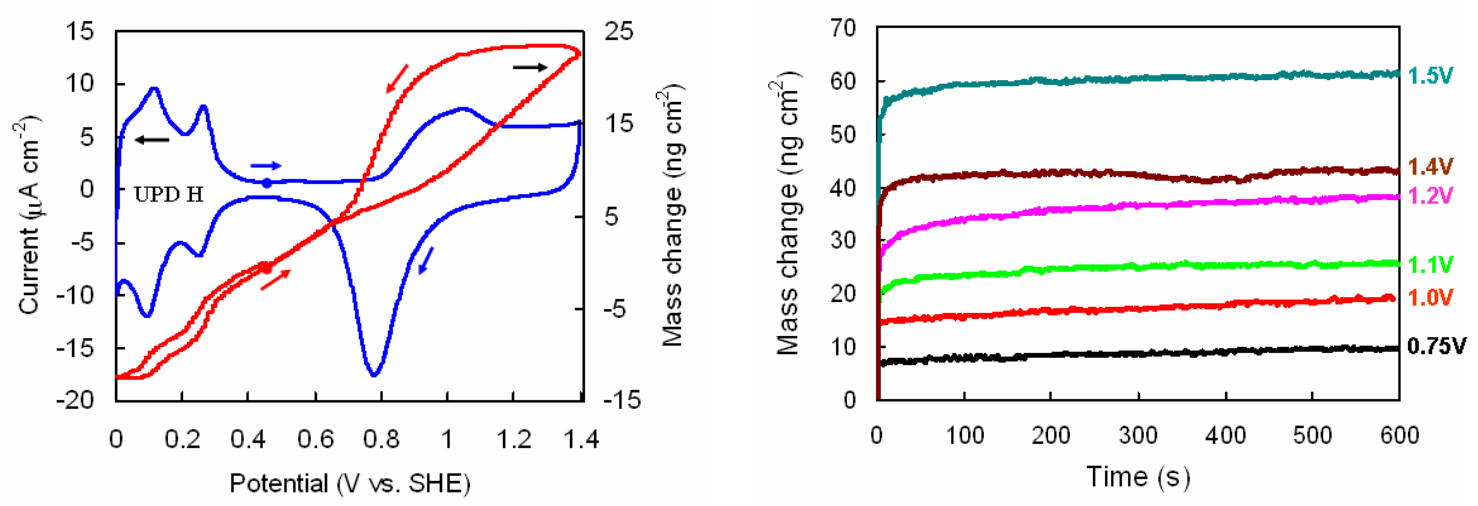

Figure 1(left): Cyclic voltammogram and corresponding mass change response of an electrodeposited $P t-Q C M$ in deaerated $0.5 \mathrm{M} \mathrm{H}_{2} \mathrm{SO}_{4}$ solutions at $0.01 \mathrm{~V} \mathrm{~s}^{-1}$. Figure 2(right): Mass change observed at EQCM during potential step of Pt samples from a hold potential of $0.45 \mathrm{~V}$ to various potentials in $0.5 \mathrm{M}$ $\mathrm{H}_{2} \mathrm{SO}_{4}$ solutions at $25^{\circ} \mathrm{C}$. Surface coverage was estimated by compensating the mass change at potential of zero charge at $0.27 \mathrm{~V}$.

On the other hand, the hysteresis in the mass change response was observed in between $0.65 \sim 1.4 \mathrm{~V}$ (Pt-oxide region). In the positive scan, the mass increased linearly with a slope of $(\Delta \mathrm{W} / \Delta \mathrm{E})=16.0 \mathrm{ng} \mathrm{cm}^{-}$ ${ }^{2} \mathrm{~V}^{-1}$ in the potential range of $0.65 \sim 0.95 \mathrm{~V}$, which was slightly smaller than that $\left(23.2 \mathrm{ng} \mathrm{cm}^{-2} \mathrm{~V}^{-1}\right)$ in the $\mathrm{DL}$ region $(0.45 \sim 0.65 \mathrm{~V})$. Further positive potential scan increased the mass with a larger slope (30.7 $\mathrm{ng}$ $\mathrm{cm}^{-2} \mathrm{~V}^{-1}$ ) in the potential range of $0.95 \sim 1.4 \mathrm{~V}$. This increase of the mass in this region would be attributed to the formation of platinum oxides according to equation (3),

$$
\mathrm{Pt}+\mathrm{H}_{2} \mathrm{O} \rightarrow \mathrm{Pt}-\mathrm{H}_{2} \mathrm{O}_{\mathrm{ad}} \rightarrow \mathrm{PtO}+2 \mathrm{H}^{+}+2 \mathrm{e}^{-}
$$

This is confirmed from the fact that the ratio $(\Delta \mathrm{W} / \Delta \mathrm{Q})$ of the mass gain $\Delta \mathrm{W}=18.7 \times 10^{-9} \mathrm{~g} \mathrm{~cm}^{-2}$ to $\Delta \mathrm{Q}=3.7 \times 10^{-4} \mathrm{C} \mathrm{cm}^{-2}$ in the potential range of 0.65 to $1.4 \mathrm{~V}$ became $=5.1 \times 10^{-5} \mathrm{~g} \mathrm{C}^{-1}$, which is close to $16 / 2 \mathrm{~F}$.

\section{Potentiostatic polarization}

Figure 2 shows the mass change of the QCM at some selected potentials during initial stage of polarization of platinum electrode in $0.5 \mathrm{M} \mathrm{H}_{2} \mathrm{SO}_{4}$ solutions. As the potential was stepped from a hold potential of $0.45 \mathrm{~V}$ to a desired value, the mass change first of all increased and attained a maximum value instantaneously. Since the mass change at $0.45 \mathrm{~V}$ has the contribution from adsorption of species in the solution, starting potential for estimating mass change should be the potential of zero charge (PZC), which in case of $\mathrm{Pt}$ is $0.27 \mathrm{~V}$. The mass change increase from $0.27 \mathrm{~V}$ to $0.45 \mathrm{~V}$ was about $5 \mathrm{ng}$ (Fig. 1). Therefore, mass change value in Fig. 2 during potential step should be corrected by adding $5 \mathrm{ng} \mathrm{cm}^{-2}$.

The increase of mass change in Fig. 2 can be assigned due to formation of a chemisorbed oxygen atom $\left(\mathrm{Pt}-\mathrm{O}_{\text {chem }}\right)$ on the platinum surface or surface oxide $(\mathrm{PtO})$. The $\mathrm{Pt}-\mathrm{O}_{\text {chem }}(\mathrm{Pt}(0)-\mathrm{O}(0))$ is formed by underpotential oxidation of water molecule and $\mathrm{PtO}(\mathrm{Pt}(+2)-\mathrm{O}(-2))$ is produced by oxidation of platinum. The $\mathrm{Pt}-\mathrm{O}_{\text {chem }}$ and $\mathrm{PtO}$ are completely different in that $\mathrm{PtO}$ will chemically dissolve to $\mathrm{Pt}^{2+}$ but $\mathrm{Pt}-\mathrm{O}_{\text {chem }}$ cannot.

From the maximum in the mass change, the surface coverage at various potentials can be estimated my knowing the fact that the formation of one monolayer of PtO results in $37 \mathrm{ng} \mathrm{cm}^{-2}$ of mass change for a (111) plane surface of platinum. It can be estimated that at $0.75,1.0,1.1,1.2,1.4$, and $1.5 \mathrm{~V}$ about 0.39 , 
$0.65,0.82,1.16,1.29$ and 1.78 monolayer of $\mathrm{PtO}$, respectively was formed. This coverage was estimated by setting the mass change at $0.27 \mathrm{~V}$ (potential of zero charge of $\mathrm{Pt}$ in $\mathrm{H}_{2} \mathrm{SO}_{4}$ ) as zero. The surface coverage we have estimated is in good agreement with the model of Darling et al. ${ }^{21}$, who calculated the growth of Pt oxide as a function of potential. From the result of Fig. 2, it can be found that Pt surface get passivated after completely covered with one monolayer of $\mathrm{PtO}$ at about $1.2 \mathrm{~V}$. At potential higher than $1.2 \mathrm{~V}$, the amount of dissolution of Pt should decreases due to the formation of a thick layer of surface oxide, probably consisting of two layer structures with $\mathrm{PtO}$ as inner layer and $\mathrm{PtO}_{2}$ as outer layer ${ }^{15}$.

\section{Conclusions}

Platinum is very stable in most environment. The amount of dissolution is very low which can be suitably studied by using the electrochemical quartz crystal microbalance. The mass change response of platinum during $\mathrm{CV}$ gives information regarding the various state of platinum surface. It was found that oxidation of platinum started at above $0.65 \mathrm{~V}$ during $\mathrm{CV}$. The mass change observed under potentiostatic condition shows that platinum surface get covered by one monolayer of Pt-oxide at above $1.2 \mathrm{~V}$.

\section{Acknowledgements}

The author would like to thank Prof. Atsushi Nishikata, Tokyo Institute of Technology, Tokyo, Japan for making available all the facilities required for this work.

\section{References}

1. B. Mattsson, H. Ericsona, L. M. Torella, and F. Sundholm, Electrochim. Acta., 2000, 45, 1405.

2. M. W. Fowler, R. F. Mann, J.C. Amphlett, B.A. Peppley, and P. R. Roberge, J. Power Sources, 2002, 106, 274.

3. A. Taniguchi, B. T. Akita, B. K. Yasuda, and Y. Miyazaki, J. Power Sources, 2004, 130, 42.

4. J. Aragane, T. Murahashi, and T. Okada, J.Electrochem. Soc., 1988, 135, 844.

5. P. N. Ross, Jr, in Catalyst Deactivation, E. E. Petersen, and A. T. Bell, Editors, Marcel Dekker, new York, 1987, pp.165-178.

6. P.J.Ferreira, G.J.la O', Y.Shao-Horn, D.Morgan, R.Makharia, S.Kocha, and H.A.Gasteiger, J.Electrochem.Soc., 2005, 152, A2256.

7. T. Patterson, pre-print Archieve-American Institute of Chemical Engineers, Spring National Meeting, New Orleans, LA, 2002, p313.

8. J. Xie, D. L. Wood, D. W. Wayne, T. A. Zawodzinski, P. Atanassov, and R. L. Borup, $\quad J$. Electrochem. Soc., 2005, 152, A104.

9. A. N. Chemodanov, Y. M. Kolotyrkin, V. E. Kosmatyi, and M. A. Dembrovskii, Electrokhimiya, $1968,4,1466$.

10. K. Kinoshita, J. T. Lundquist, and P. Stonehart, J.Electroanal.Chem., 1973, 48, 157.

11. A. N. Chemodanov, Y. M. Kolotyrkin, and M. A. Dembrovskii, Electrokhimiya, 1970, 6, 460.

12. D. A. J. Rand, and R. Woods, J.Electroanal. Chem., 1972, 35, 209.

13. K. Ota, S. Nishigori, and N. Kamiya, J.Electroanal.Chem., 1988, 257, 205.

14. S. Mitsushima, S. Kawahara, K. Ota, and N. Kamiya, J.Electrochem.Soc., 2007, 154, B153.

15. X. P. Wang, R. Kumar, and D. J. Myers, Eletrochem. Solid-State Lett., 2006, 9, A225.

16. V. A. T. Dam, and F. A. de Bruijn, J.Electrochem.Soc., 2007, 154, B494.

17. P. Bindra, S. J. Clouser, and E. Yeager, J.Electrochem.Soc., 1979, 126, 1631.

18. A. P. Yadav, A. Nishikata, and T. Tsuru, Electrochim. Acta, 2007, 52, 7444.

19. G. Sauerbray, Z. Phys, 1959, 155, 206.

20. G. Jerkiewicz, G. Vatankhah, J. Lessard, M. P. Soriaga, and Y. S. Park, Electrochim. Acta, 2004, 49, 1451.

21. R. M. Darling and J. P. Meyers, J.Electrochem.Soc., 2005, 152, A242. 